\title{
O CONGRESSO DE VIENA, O TRÁFICO DE ESCRAVOS E AS CONSEQUÊNCIAS PARA PORTUGAL E BRASIL
}

\author{
THE VIENNA CONGRESS, THE SLAVE TRADE AND ITS CONSEQUENCES TO PORTUGAL AND
}

BRAZIL

Felipe Nicolau Pimentel Alamino*

\begin{abstract}
Resumo:
O presente artigo busca trazer uma perspectiva acerca da influência do Congresso de Viena sobre os Tratados bilaterais entre Portugal e o Reino Unido da Grã-Bretanha e Irlanda com relação ao tráfico de escravos, dos anos de 1815 e de 1817. Procura, também, traçar as consequências do Concerto Europeu com relação ao Brasil, no tocante à escravidão, cujos ecos podem ser encontrados no Tratado anglo-brasileiro de 1826.

Palavras-chave: Direito Internacional. Congresso de Viena. Tráfico de escravos. Escravidão no Brasil. Tratados anglo-portugueses.
\end{abstract}

\begin{abstract}
:
The paper strives to bring a perspective about the influence of the Vienna Congress on the bilateral Treaties of 1815 and 1817 between Portugal and the United Kingdom of Great Britain and Ireland in relation to the slave trade. It tries to mark the consequences of the European Concert to Brazil, about slavery issues, whose echoes can be found in the Anglo-Brazilian Treaty of 1826.
\end{abstract}

Keywords: International Law. Vienna Congress. Slave trade. Slavery in Brazil. Anglo-Portuguese treaties.

Introdução

Ao final das Guerras Napoleônicas as maiores potências europeias reuniramse para resolver as principais questões relativas às consequências territoriais, bem como o equilíbrio que deveria haver entre as principais forças políticas, econômicas e militares do velho continente, com o objetivo de que não ressurgissem ideias como as que permitiram a ascensão de Bonaparte ao poder na França.

Foi em meio a estas discussões que o governo britânico elevou à matéria multilateral a questão da abolição do comércio de escravos. Graças a fortes pressões internas da opinião pública, a Grã-Bretanha conseguiu influenciar politicamente as principais nações coloniais à época: França, Espanha e Portugal, a discutir o futuro do comércio que passava a ser considerado, então, aviltante à humanidade.

\footnotetext{
* Mestrando em Direito pela Universidade de São Paulo - USP. 
O presente trabalho pretende demonstrar como a política britânica conseguiu incluir o tema do tráfico de escravos no Concerto Europeu e como as discussões originadas em Viena, em 1815, acabaram influenciando os Tratados que seriam negociados e assinados por Portugal, limitando o comércio de escravos que, ao menos no primeiro momento, passaria a ser permitido apenas ao sul da linha do Equador, bem como, as consequências jurídicas destas disposições ao Brasil.

\section{O Congresso de Viena e o Ato XV de sua Ata Final}

Com o exílio de Napoleão Bonaparte, na ilha de Elba, após as Guerras Napoleônicas, as potências vencedoras ${ }^{1}$ reuniram-se em Viena para refazer a ordem internacional, ${ }^{2}$ o que resultaria na formatação de um sistema político restaurativo, redesenhando o mapa político europeu, em uma tentativa de frear os anseios republicanos advindos da Revolução Francesa e de se recuperar, no que fosse possível, o absolutismo. Este novo sistema político impediria que guerras de grandes proporções surgissem, tendo a Europa vivido um período de paz, bastante longevo, sem o enfrentamento direto das Grandes Potências europeias, sendo a única exceção a guerra da Crimeia (1853-1856) (KISSINGER, 2012, p. 62).

Baseada nos princípios de equilíbrio de poder, as potências reunidas no Congresso de Viena tentaram balancear as forças militares, as forças econômicas e as forças políticas, dividindo territórios em duas ou mais entidades políticas e anexando outros aos seus domínios. Outro fator central do Congresso foi o princípio da legitimidade, fundamento que levaria o rei Luís XVIII ao trono na França, numa tentativa de se resgatar os valores considerados legítimos anteriores à Revolução Francesa, tentando bloquear o avanço liberal $^{3}$ e se alcançar o status quo ante (KISSINGER, 2012, p. 63-70).

A ata final do Congresso de Viena, de 1815, englobou diversos tratados em que as Potências reunidas mostram suas preocupações relativas a questões territoriais, estabelecendo limites e fronteiras entre Estados, bem como, questões referentes a

As potências vencedoras são Áustria, Prússia, Rússia e a Grã-Bretanha, porém, a elas seria somada a França do recém restaurado rei Luís XVIII, posteriormente, embora também participassem das discussões Espanha, Portugal, Suécia, Dinamarca entre outros Estados de menor expressão política.

2 Embora com maiores consequências para o continente europeu, pode-se chamar de ordem internacional, haja vista que as Guerras Napoleônicas influenciaram os desdobramentos político-jurídicos das ex-colônias europeias nas Américas.

3 Como formas de se alcançar as medidas pretendidas, constituíram-se a Quádrupla Aliança (Grã-Bretanha, Prússia, Áustria e Rússia), com o objetivo de barrar qualquer ameaça de cunho liberal vinda da França, e a Santa Aliança (Áustria, Prússia e Rússia), baseada na religião cristã e no respeito ao Antigo Regime, com valores bastante conservadores. 
emigração, questões relativas à navegação e ao comércio e, no que afeta de maneira mais direta ao presente trabalho, questões referentes à abolição do tráfico de escravos. ${ }^{4}$

$\mathrm{O}$ Ato XV, datado de oito de fevereiro de 1815 , anexo à ata final, ${ }^{5}$ traz a Declaração das Potências acerca da abolição do tráfico de negros. ${ }^{6}$ Neste documento, as potências reunidas reconhecem que o tráfico de escravos ${ }^{7}$ é repugnante aos princípios de humanidade e de moralidade universal, que embora o fim seja difícil de se alcançar, todos os países civilizados deveriam trabalhar para que o tráfico fosse suprimido de forma mais rápida o possível, com o objetivo de acabar, numa tradução literal dos termos do Ato, com a calamidade que há muito desola a África, degrada a Europa e aflige a humanidade.

O documento traz que, embora seja uma medida de necessária atenção, a Declaração geral não poderá prejudicar o período que cada Potência considere necessário para abolir o tráfico, deixando assim como discricionário a cada Estado envolvido o tempo no qual deverá chegar a este marco.

Pode-se entender assim que o Ato XV é uma declaração de princípios pelos quais os Estados reunidos no sistema do Concerto Europeu se nortearão em suas relações, com o objetivo de se chegar à abolição universal a ser trabalhada como objeto de negociações entre as Potências, por meio de esforços conjuntos.

Embora seja vazia no sentido de não estabelecer um prazo, a Declaração conjunta das Potências exorta que os Estados procurem da maneira mais breve o possível, sem que trabalhem contra, ou seja, acelerem ou aumentem o tráfico de escravos, os ditames do documento.

Este documento, ainda que importante por ser considerado o primeiro ato multilateral na matéria (DECAUX, 2009, p. 36), como já afirmado, serviu como um instrumento aos Estados se obrigarem a negociar futuramente sobre a temática, sem perder o foco central, a erradicação do tráfico de escravos, entre os Estados europeus e suas colônias.

Destarte, foi durante as negociações do Congresso de Viena e do Ato XV que, Portugal e Grã-Bretanha estabeleceram o primeiro tratado definindo limites concretos ao tráfico de escravos para os territórios de possessão portuguesa, o que é extremado interesse desde uma perspectiva brasileira.

4 Chamado no documento de abolição do tráfico de negros.

5 ACTE XV. Déclaration des puissances sur l'abolition de la traite des nègres. In: ACTE du congrès de vienne du 9 juin 1815, avec ses annexes, 1815, Vienne. Disponível em: <gallica.bnf.fr/ark:/12148/bpt6k91227n/ f310.image/>. Acesso em: 18 jun. 2017.

6 Em uma tradução literal do título da Declaração no original, em francês.

7 O documento só trata dos escravos provenientes do continente africano, uma razão pela qual a versão original, em francês, optou por trazer o conceito como tráfico de negros. 
2. Os esforços britânicos

Ao acabar com seu tráfico transatlântico a partir do ano 1807 (DECAUX, 2009, p. 35), a Grã-Bretanha engajou-se ativamente para acabar com o tráfico internacionalmente, sendo este uma das matérias centrais em suas discussões diplomáticas na primeira metade do século XIX. Consequentemente, os britânicos, durante os anos de 1810 e 1814, assinaram tratados com Suécia, Dinamarca e Portugal, que restringiam as atividades relativas ao comércio de escravos (REICH, 1968, p. 129), embora com este último país, a matéria fosse tema de um artigo específico e com os primeiros a temática fosse pouco sensível, haja vista que tais Estados não faziam uso do tráfico transatlântico de escravos.

Ainda no ano de 1814, o Reino Unido da Grã-Bretanha e Irlanda assinaria com a França o Tratado de Paris, que obrigava os dois Estados a instar as demais potências a procurar abolir definitivamente o tráfico de escravos no Congresso de Viena, conforme tentou-se mostrar.

Os esforços britânicos consistiam em duas etapas. Por um lado, deveriam negociar tratados com as nações chamadas civilizadas ${ }^{8}$ e com as tribos africanas para a supressão do tráfico de escravos e de outro lado, para que houvesse execução das normas, os britânicos manteriam fortes na costa do continente africano e cruzadores patrulhando suas águas, em um esforço de policiamento (HILL, 1931, p. 169).

Em matéria relativa aos tratados de supressão do tráfico com as nações civilizadas, o Reino Unido buscou o inicialmente, durante as discussões que envolviam o Congresso de Viena, pactuar diretamente com a França, Portugal e Espanha.

Sua linha de atuação consistiria em ceder empréstimos a estes Estados, como no caso da Espanha (REICH, 1968, p. 133), ou de forçar politicamente a França a cooperar com os objetivos britânicos, na esperança de que, caso esta decretasse o fim do tráfico de escravos, sua decisão persuadiria Portugal e Espanha a fazer o mesmo, levando a uma supressão conjunta deste tipo de comércio (FLADELAND, 1966, p. 355).

Como ao final das Guerras Napoleônicas ${ }^{9}$ o Reino Unido havia conquistado a posse de colônias francesas, o retorno destas ao poder francês poderia ser usado como

8 Ao chamar nações civilizadas, à época entendia-se apenas os Estados europeus e os Estados Unidos da América, sobretudo os Estados da Europa Ocidental.

9 Embora se destaque o fato de que a Revolução Francesa tenha ainda em 1792 abolido a escravidão, porém, o grande inimigo das Potências Europeias, Napoleão Bonaparte, ao chegar ao poder, reinstalaria este instituto. Posteriormente, enquanto as Potências encontravam-se reunidas em Viena, Napoleão, no governo dos cem dias, quando voltara ao poder na França, talvez como forma de aplacar a pressão britânica, decretou, novamente, a abolição da escravidão e o fim do tráfico, o que seria revogado pelo governo de Luís XVIII, ainda que mantida a abolição do comércio de escravos, só se encerrando em definitivo após a Revolução de 1848. 
barganha para poder se estabelecer o final do tráfico. O parlamento britânico sofria, no período, fortes pressões da opinião pública nativa para que só houvesse o estorno das colônias francesas com a condição de que não mais escravos africanos fossem importados para estas dependências (FLADELAND, 1966, p. 357).

Esta pressão britânica para que a França abolisse a escravidão e o tráfico não estaria de acordo com a opinião pública francesa ${ }^{10}$ segundo Talleyrand, ${ }^{11}$ não sendo possível a este país a abolição imediata. Porém, durante as tratativas do Congresso de Viena, os britânicos envidaram esforços para que fosse estabelecido com os franceses um período de cinco anos para que se abolisse o tráfico, o que, por um lado, garantiria que a França aumentasse e estocasse o número de cativos em suas colônias (PUTNEY, 1975, p. 414).

Outra forma de se tentar convencer a França a ceder às pressões britânicas para a efetivação da abolição do tráfico seria a barganha territorial. Para que os franceses aceitassem o fim imediato deste tipo de comércio, ${ }^{12} \mathrm{o}$ Duque de Wellington, plenipotenciário britânico em Viena, ${ }^{13}$ ofereceu três milhões de libras ou a compensação à França com a cessão de uma nova colônia em território americano, no caso, a ilha de Trinidad (REICH, 1968, p. 134). Porém, esta proposta que não foi aceita pelos representantes franceses, tendo Tayllerand levado a questão às reuniões, tentando-se estabelecer uma declaração conjunta das oito potências europeias (Grã-Bretanha, França, Espanha, Portugal, Rússia, Prússia, Áustria e Suécia), com o intuito de se discutir a possibilidade da abolição ou, ao menos, a restrição do comércio de escravos.

Todavia, esta iniciativa não fora bem recebida pelos representantes de Portugal e de Espanha, Conde Palmela e Conde Labrador respectivamente, pois consideravam que apenas as quatro potências coloniais, ou seja, Grã-Bretanha, França, Portugal e Espanha teriam legitimidade e interesse em participar das discussões sobre o tema, não aceitando inicialmente a inclusão de países que não praticavam a escravidão (PUTNEY, 1975, p. 422). Este entendimento, porém, não era compartilhado por Castlereagh, nem pela opinião pública britânica, uma vez que afirmavam que este assunto, por sua natureza, era de interesse da humanidade e portanto, não poderia ser excluída

10 Se do lado francês a opinião pública não aceitava o fim do tráfico, pelo lado britânico, os abolicionistas, ganhando força na opinião pública de seu país faziam movimentação de se instaurar um boicote internacional de produtos coloniais provenientes dos países que não cooperavam com o esforço de se acabar com o comércio de escravos (FLADELAND, 1966, p. 362).

11 Diplomata histórico francês, representante deste país nas reuniões do Congresso de Viena.

12 O que não se conseguiu, passando a ser feito de forma paulatina, sendo abolido inicialmente apenas ao norte da linha do Equador.

13 Substituíra Lorde Castlereagh, como primeiro plenipotenciário. 
nenhuma potência das tratativas, o que no fim, acabou prevalecendo (REICH, 1968, p. 136-137).

Graças aos esforços britânicos, e às manobras francesas, as discussões sobre o fim do tráfico de escravos foram levadas ao Congresso de Viena, sendo decidido de forma multilateral, como já demonstrado, exortando os Estados, por influência (REICH, 1968 , p. 137) portuguesa e espanhola, ${ }^{14}$ a acabarem com este comércio à medida que acharem conveniente para as suas economias. Esta medida levou o Reino Unido de GrãBretanha e Irlanda a procurar firmar tratados bilaterais com as potências coloniais.

Porém, antes de avançarmos às tratativas luso-britânicas, ainda vale ressaltar que durante o Concerto Europeu, no governo dos cem dias, Napoleão, que fugira da ilha de Elba, ao retomar o poder na França, percebe que um dos grandes entraves às relações Anglo-francesas seria a questão relativa à escravidão.

Assim, enquanto o Congresso de Viena encontrava-se em sessão, proclamaria no dia 29 de março de 1815 um decreto de cinco artigos em que se estabelecia a abolição do comércio de escravos, não sendo permitido a nenhum barco a entrada em qualquer porto francês, ou de suas colônias em qualquer parte do globo, com escravos para o comércio, tampouco sendo franqueado a qualquer cidadão francês a capacidade de empreender tais atos, passível de risco do confisco do navio e de sua carga, após julgamento em Cortes francesas, aos que violassem o decreto (PUTNEY, 1975, p. 424425).

Ao derrotar novamente Napoleão, na batalha de Waterloo, que levou o Imperador francês ao seu exílio final na ilha de Santa Helena, os esforços britânicos passaram a ter como meta levar o restaurado governo francês a reconhecer o avanço ocorrido no período em que Bonaparte retornara ao poder, todavia, este reconhecimento só seria levado a cabo com a assinatura do Tratado de Paz entre a França e a Grã-Bretanha, de novembro de 1815 , onde se procurava estabelecer a abolição universal da escravidão (PUTNEY, 1975, p. 427), instrumento que, somado ao decreto imperial de março do mesmo ano, pelo rei Luís XVIII, levaria a França a abolir o comércio de escravos.

Agora, podemos passar às tratativas entre Grã-Bretanha e Portugal, ocorridas durante o Congresso de Viena, visando a tornar ilegal o comércio de escravos, com consequências diretas a sua colônia nas Américas, o Brasil.

3. Portugal e Grã-Bretanha: os tratados de 1815 e de 1817

Embora as negociações britânicas com Portugal relativas ao comércio de escravos remontem ao Tratado de Amizade e de Aliança de 19 de fevereiro de 1810, que

14 Uma vitória de seu corpo diplomático. 
continha uma provisão de que o governo português não transportaria escravos negros de partes da África as quais não tivessem domínio (HILL, 1931, p. 170), o que pode ser considerada a primeira obrigação portuguesa a restringir e gradualmente abolir o comércio de escravos (BETHELL, 2002, p. 29-30), foi apenas durante as reuniões do Concerto Europeu que evoluíram as tratativas sobre o tema.

Os esforços para que houvesse o fim do tráfico tinham como princípio norteador esclarecer que o comércio de escravos é um mal à humanidade e exortar que as nações busquem, o quanto antes, acabar com este procedimento, por si próprias, conforme se veria na Declaração sobre o Tráfico de Escravos, já comentada no presente trabalho.

Como já salientado, os britânicos, durante as reuniões do novo sistema europeu em formação, buscaram com seus parceiros comerciais estabelecer limites ao tráfico de escravos.

O Tratado entre portugueses e britânicos (1815), negociado e assinado em Viena, durante o Congresso, dias antes de a Declaração ser assinada pelos plenipotenciários ${ }^{15}$ garantia que qualquer vassalo da Coroa de Portugal estaria proibido de comprar ou traficar em qualquer parte da Costa da África ao Norte do Equador, sob qualquer pretexto, por qualquer modo que seja, salvo aqueles que já tivessem saído dos portos do Brasil antes da ratificação do Tratado (art. $1^{\circ}$ ). Trazia também a garantia que não seriam estorvados os interesses comerciais das naus que trafegassem segundo as leis lusitanas ao sul do Equador, além de dispor que as duas partes contratantes se reservariam o direito de futuramente cessar universalmente o comércio de escravos (arts. $2^{\circ}$ e $4^{\circ}$, respectivamente). ${ }^{16}$

O Tratado constou também de um artigo adicional com o objetivo de garantir a migração de colonos portugueses. Este artigo permitia que o súdito português pudesse transferir-se de uma área a outra das possessões lusitanas com seus escravos, sem estar limitado pela linha do Equador, contando que o fizesse em nau que não estivesse arranjada para o tráfico e que fosse munido dos documentos necessários para qualificálo como tal, diferenciando-o de um comerciante de escravos, garantindo assim, que não sofresse qualquer entrave às suas liberdades.

15 O Tratado Anglo-português fora assinado em 22 de janeiro de 1815, enquanto a Declaração multilateral sobre o tráfico de escravos é de 8 de fevereiro de 1815. Ambos são consequências das mesmas negociações, procurando o Reino Unido da Grã-Bretanha e Irlanda, resolver, em paralelo com Portugal, o problema do tráfico que, pelo documento multilateral só daria diretrizes gerais e uma demonstração de princípios.

16 PORTUGAL. Tratado da abolição do trafico de escravos em todos os lugares da Costa de Africa ao Norte do Equador, entre os muito altos, e muito poderosos senhores o Principe Regente de Portugal, e El-Rei do Reino Unido da Grande Bretanha e Irlanda: feito em Vienna pelos Plenipotenciarios de huma e outra Corte em 22 de janeiro de 1815, e ratificado por ambas. Rio de Janeiro: Na Impressão Regia, 1815. Disponível em: <http://bd.camara.gov.br/bd/handle/bdcamara/1764>. Acesso em: 18 de jun. 2017. 
O Tratado Anglo-português de $1815^{17}$ embora proibisse o comércio de escravos ao norte do Equador, não garantia sua aplicação, como qualquer lei, não era autoaplicável. Assim, para que não viesse a ser vazio em seus objetivos, as partes contratantes, dando continuidade na tentativa de acabar com o tráfico, negociaram e assinaram a Convenção Adicional Portugal-Inglaterra sobre o Tráfego de Escravos, de 28 de julho de 1817.

Este Tratado trazia em seu corpo disposições que permitiam o direito de busca, o que também era previsto em Tratados análogos estabelecidos entre a GrãBretanha e a Espanha e os Países Baixos, já que o tráfico de escravos, quando contrário ao acordado pelas potências, poderia ser considerado como pirataria e as naus responsáveis por este tipo de comércio, como tal eram tratadas (FLADELAND, 1966, 367-369).

O objetivo principal deste Tratado é garantir a ambos os Governos o direito de vigiar mutuamente seus vassalos com o direito de visita aos navios de pavilhão britânico ou sob o controle de súditos britânicos e aos navios de pavilhão português ou sob controle de portugueses, com o objetivo de garantir a aplicação do Tratado de 1815 e de se combater o comércio ilegal de escravos.

Para que houvesse maior controle dos navios pelas partes contratantes, o art. $4^{0}$ deste Tratado ${ }^{18}$ estabelecia um passaporte identificador do navio, que deveria ser escrito em língua portuguesa, com tradução autêntica em inglês, assinada pelo Ministro da Marinha.

Em havendo motivo razoável, estariam autorizados os navios de ambas as Marinhas, munidos de Instruções Especiais, visitar as naus mercantes de ambas as nações, garantindo, portanto, mutuamente o direito de visita, tanto a navios de guerra britânicos aos navios portugueses mercantes quando a navios de guerra portugueses a navios mercantes britânicos, com o objetivo de deter, levar e fazer julgar em Tribunais estabelecidos para este fim (art. $5^{\circ}$ ).

Todavia, a reciprocidade não passaria de um mito (BETHELL, 1965, p. 763). Portugal nunca teria exercido seu direito de visita a navios britânicos. Apesar disto,

17 As tratativas entre Portugal e o Reino Unido da Grã-Bretanha e Irlanda tentaram estipular um prazo de cinco anos para que se chegasse à abolição do comércio, o que o Conde de Palmela teria refutado por não ser tempo suficiente ao país para preparar tão grande mudança econômica, passando inicialmente para oito anos, só depois conseguiu-se que se limitasse, inicialmente, a proibição ao Norte do Equador, um triunfo da diplomacia portuguesa, pois se deixava o comércio ao sul em aberto para ser discutido em um futuro acordo (BETHELL, 2002, p. 34-35).

18 PORTUGAL. Convenção addicional ao Tratado de 22 de janeiro de 1815: entre os muito altos, e muito poderosos senhores El-Rei do Reino Unido de Portugal, do Brazil, e Algarves, e El-Rei do Reino Unido da Grande Bretanha, e Irlanda: feita em Londres pelos Plenipotenciarios de huma e outra Côrte em 28 de julho de 1817, e ratificada por ambas. Rio de Janeiro: Na Impressão Regia, 1817. Disponível em: <http:// bd.camara.leg.br/bd/handle/bdcamara/1866>. Acesso em: 18 jun. 2017. 
duas Comissões mistas foram formadas, conforme constava do Tratado de 1817, art. $8^{\circ}$, compostas por súditos das duas Coroas, com o objetivo de julgar os navios apresados, sendo estabelecidas nas duas costas do Oceano Atlântico, uma no Brasil e outra em África. ${ }^{19}$

O Tratado trazia anexos instrumentos de suma importância para a aplicação do que fora estabelecido em 1815, como o formulário de passaporte, estabelecendo as regras e discriminações que deveriam estar contidas no documento para qualificar um navio como apto a praticar o comércio considerado legal a sul do Equador; Instruções para os navios de guerra das duas nações, garantindo as diretrizes que deveriam seguir as naus para efetuar abordagens, estabelecendo a distância da Costa que poderiam exercer sua jurisdição e o Regulamento para Comissões mistas.

As Comissões Mistas, estabelecidas pelo art. $2^{\circ}$ do documento em anexo $\mathrm{n}$. 3 ao Tratado de 1817, deveriam ser compostas por um comissário juiz e um comissário árbitro, capazes de ouvir e decidir, sem apelação, todos os casos de captura dos navios de escravatura que possam ser submetidos a eles.

Aos juízes e árbitros era facultado o poder de decidir conforme seu livre convencimento, não devendo dar preferência nem aos captores, nem aos reclamantes. Finalmente, cada Comissão deveria ser composta também por um Secretário, capaz de registrar todos os Atos da Comissão.

$\mathrm{O}$ art. $8^{\circ}$ do mesmo documento estabelecia qual destino dos navios declarados boa preza. Afirmava que tanto o casco quanto a carga, à exceção dos escravos, deveriam ser vendidos em leilão público, sendo beneficiados os dois governos. ${ }^{20}$

Já no tocante aos escravos, estes deveriam receber da Comissão mista uma Carta de Alforria, sendo consignados ao Governo do país que residir a Comissão que tiver dado a sentença para serem empregados em qualidade de criados ou de trabalhadores livres a cargo do Governo, mas não o seu retorno ao lugar onde fora apresado ou vendido.

Finalmente, o artigo adicional à Convenção garantiria que esta continuaria válida por quinze anos a serem contados após Portugal abolir em definitivo a escravidão. ${ }^{21}$

As Comissões mistas dos dois lados do Oceano Atlântico acabaram por ser estabelecidas apenas em 1819, sendo uma no território britânico em África, em Freetown, Serra Leoa e a outra, no Rio de Janeiro, Brasil. ${ }^{22}$

19 Haveria outra Comissão a ser estabelecida em Londres também mista, conforme o art. $9^{\circ}$ do Tratado.

20 O documento também estabelecia uma quota de direito de preza ao captor, assim como também, em caso de equívoco, estabeleceria um castigo cabido ao captor que tiver se excedido na abordagem, proporcional à infração cometida.

21 Ver. Nota de rodapé n. 27.

22 Ver. Nota de rodapé n. 32. 
Porém, em 1822, o Brasil tornar-se-ia independente de Portugal, o que, devido às disposições dos Tratados de 1815 e de 1817, que franqueavam apenas a portugueses o transporte de escravos a suas possessões ao sul do Equador, tornava todo o comércio português a partir da separação de Portugal e do Brasil considerado ipso facto ilegal (BETHELL, 1965, p. 764), nem mesmo um comércio entre brasileiros e possessões portuguesas na África seria permitido à luz daqueles instrumentos legais.

Embora o tráfico de escravos fosse considerado ilegal, especificamente quando analisada a inteligência do art. $4^{\circ}$ do Tratado de 1815 e dos arts. $2^{\circ}, 4^{\circ}$ do Tratado de 1817 e art. $9^{\circ}$ do Anexo n. 2, continuou a existir ao sul do Equador, alimentando um mercado brasileiro independente.

Este fato levou o Reino Unido da Grã-Bretanha e da Irlanda a aplicar sua política externa, que já vinha sendo usada junto a Portugal com o objetivo de cessar o tráfico de escravos, ao Brasil, tendo grande destaque na primeira metade do século XIX na relação destes dois países, havendo em 1826 a negociação e assinatura de um Tratado entre o Brasil e a Grã-Bretanha que estabelecia que não seria considerado legítimo sob qualquer pretexto o comércio de escravos da Costa da África ao Brasil, implicando em pirataria o descumprimento do acordado e resgatando o estabelecido no Tratado de 1817 para o novo país independente.

Assim, as Comissões outrora estabelecidas entre Portugal e os britânicos passariam a ser válidas entre estes e o Brasil (art. $2^{\circ}$ ), ${ }^{23}$ alterando desta maneira os signatários, mas mantendo-se a estrutura apta a julgar as infrações cometidas pelos traficantes de escravos, bem como o direito de abordagem e apresamento de navios por ambas as partes, embora o tráfico só se tornasse definitivamente ilícito apenas no segundo reinado, por intermédio da Lei aprovada em 4 de setembro de $1850,{ }^{24}$ após forte pressão britânica, não apenas política, mas também com o uso da força como com o deslocamento de sua esquadra para reprimir naus de transporte de escravos, além de bloquear portos como o de Santos (PARRON, 2011, p. 236-237).

Conclusão

A opinião pública no Reino Unido da Grã-Bretanha e Irlanda operou grandes mudanças em suas linhas políticas, com a pressão aos seus representantes por transformar o tráfico de escravos em ilícito, não só em seus territórios como também em todo o globo.

\footnotetext{
23 BRASIL. Convenção para a abolição do tráfico de escravos. Disponível em: <http://dai-mre.serpro.gov. br/atos-internacionais/bilaterais/1826/convencao-para-a-abolicao-do-trafico-de-escravos/>. Acesso em: 19 jun. 2017.

24 Lei Eusébio de Queirós.
} 
Com a tentativa de rearranjo de rumos na Europa, por meio do Congresso de Viena e sucessivas reuniões que vieram depois, os diplomatas britânicos pressionaram as demais potências a acabar com o comércio de seres humanos, assim, favorecendo o interesse da opinião pública, bem como os interesses econômicos deste país.

Foi acrescido à Ata final do Congresso de Viena uma manifestação de que o comércio de escravos era aviltante à humanidade e, portanto, deveria ser proibido. Para que se chegasse à concordância com este dispositivo, os britânicos recorreram ao apoio de nações não coloniais como Prússia, Áustria e Rússia, o que levou Portugal e Espanha, principais nações coloniais e escravistas a protestar, ainda que, sem conseguir barrar a elaboração do documento.

O Congresso de Viena daria, portanto, as diretrizes de como deveriam ser os esforços para se acabar com o tráfico, sendo o primeiro documento multilateral da história a tratar do tema. Sob as orientações da Ata final, os britânicos procuraram as nações que faziam uso do trabalho escravo para tentar, uma a uma, tecer tratados com o fulcro de extinguir ou, ao menos, limitar o alcance do comércio.

Assim, com as ideias maturadas em Viena, em 1815, há uma nova série de tratativas para Portugal, e consequentemente para o Brasil, objetivando o fim do tráfico.

Se o primeiro tratado, de 1810, dava horizontes ainda estreitos acerca da necessidade de se limitar o comércio de escravos, o Tratado, negociado e assinado entre Portugal e a Grã-Bretanha durante o Congresso de Viena (1815), conseguiu dar novos rumos à progressiva limitação, com a proibição do comércio partindo de portos ao norte da linha do equador.

O Tratado de 1815 seria fortalecido com a negociação e assinatura de um novo Tratado em 1817. Embora se mantivessem os limites geográficos do Tratado negociado em Viena, este novo instrumento garantia exequibilidade ao primeiro, permitindo que embarcações militares de ambos os países tivessem direito de visita a naus suspeitas de terem praticado tráfico ao norte do globo terrestre.

Outra garantia extra que o novo Tratado trazia eram os documentos que deveriam ser usados pelas naus para se garantir o livre exercício de visita, bem como para se demonstrar que participavam do comércio legal de escravos, ou seja, proveniente do sul da linha do equador.

Embora o tráfico de escravos ao Brasil só tenha se extinguido já no Segundo Reinado, 1850, com o país independente, tencionou-se mostrar que suas origens mais firmes remontam do Congresso de Viena em 1815.

Este, ao reunir as principais potências europeias à época, trouxe novas diretrizes ao direito, estabelecendo multilateralmente o princípio de que o tráfico de escravos, bem como a escravidão eram uma mancha à humanidade, devendo ser combatido, o que acabou ocorrendo, sempre por meio de tratados bilaterais, como os 
assinados por Portugal em 1815 e 1817, tendo o Reino Unido da Grã-Bretanha e Irlanda como o principal negociador e entre este Estado e o Brasil, em 1826.

São Paulo, 20 de junho de 2017.

\section{Referências}

BETHELL, Leslie M. Britain, Portugal and the suppression of the Brazilian slave trade: the origins of Lord Palmerston's act of 1839. The English Historical Review, Oxford, v. 80, n. 317, p. 761-784, Oct. 1965.

- A abolição do comércio brasileiro de escravos: a Grã-Bretanha, o Brasil e a questão do comércio de escravos 1807-1869. Tradução de Luís A. P. Souto Maior. Brasília: Senado Federal, Conselho Editorial, 2002.

DECAUX, Emmanuel. Les formes contemporaines de l'esclavage. Leiden/Boston: Martinus Nijhoff Publishers, 2009.

FLADELAND, Betty. Abolitionist pressures on the concert of Europe, 1814-1822. The Journal of Modern History, Chicago, v. 38, n. 4, p. 355-373, Dec., 1966.

HILL, Lawrence F. The abolition of the African slave trade to Brazil. The Hispanic American Historical Review, Durham, v. 11, n. 2, p. 169-197, May 1931.

KISSINGER, Henry. Diplomacia. Tradução de Saul S. Gefter e Ann Mary Fighiera Perpétuo. Tradução revista de Heitor Aquino Ferreira. São Paulo: Saraiva, 2012.

PARRON, Tâmis. A política da escravidão no Império do Brasil, 1826-1865. Rio de Janeiro, Civilização Brasileira, 2011.

PUTNEY, Martha. The slave trade in French diplomacy from 1814 to 1815. The Journal of Negro History, Washington DC, v. 60, n. 3, p. 411-427. July 1975.

REICH, Jerome. The slave trade at the Congress of Vienna: a study in English public opinion. The Journal of Negro History, Washington DC, v. 53, n. 2, p. 129-143, Apr. 1968.

\section{Documentos}

ACTE XV. Déclaration des puissances sur l'abolition de la traite des nègres. In: ACTE du congrès de vienne du 9 juin 1815, avec ses annexes, 1815, Vienne. Disponível em: <gallica.bnf.fr/ark:/12148/ bpt6k91227n/f310.image/>. Acesso em: 18 jun. 2017.

BRASIL. Convenção para a abolição do tráfico de escravos. Disponível em: < http://dai-mre.serpro. gov.br/atos-internacionais/bilaterais/1826/convencao-para-a-abolicao-do-trafico-de-escravos/>. Acesso em: 19 jun. 2017. 
PORTUGAL. Convenção addicional ao Tratado de 22 de janeiro de 1815: entre os muito altos, e muito poderosos senhores El-Rei do Reino Unido de Portugal, do Brazil, e Algarves, e El-Rei do Reino Unido da Grande Bretanha, e Irlanda: feita em Londres pelos Plenipotenciarios de huma e outra Côrte em 28 de julho de 1817, e ratificada por ambas. Rio de Janeiro: Na Impressão Regia, 1817. Disponível em: <http://bd.camara.leg.br/bd/handle/bdcamara/1866>. Acesso em: 18 jun. 2017.

- Tratado da abolição do trafico de escravos em todos os lugares da Costa de Africa ao Norte do Equador, entre os muito altos, e muito poderosos senhores o Principe Regente de Portugal, e El-Rei do Reino Unido da Grande Bretanha e Irlanda: feito em Vienna pelos Plenipotenciarios de huma e outra Corte em 22 de janeiro de 1815, e ratificado por ambas. Rio de Janeiro: Na Impressão Regia, 1815. Disponível em: <http://bd.camara.gov.br/bd/handle/bdcamara/1764>. Acesso em: 18 de jun. 2017. 
